\title{
A study on social skill of adolescent boys and girls across socio-economic groups
}

\author{
Pallavi Pandey, Anshu and Anjali Mathur
}

Received: 09.10.2020; Revised: 08.11.2020; Accepted: 25.11.2020

See end of the paper for authors' affiliations Pallavi Pandey Department of Human Development, Ethelind College of Community Science, Sam Higginbottom University of Agriculture, Technology and Sciences, Prayag Raj (U.P.) India Email : pallavi.lavipandey@ gmail.com
ABSTRACT : The purpose of present study is to examine the social skill of adolescent boys and girls across three socio-economic groups ((upper, middle and lower socio-economic group). The sample of study was comprised of 450 adolescents ( 225 boys and 225 girls) between the age group of 13 to 18 years belonging to three socio-economic groups (upper, middle and lower socio-economic group) from Prayagraj city of Uttar Pradesh. Stratified random sampling technique was followed in the study. Kuppuswamy's socio-economic scale (1961) was administered to access the socio-economic status of the adolescents which is modified by Gururaj and Maheshwaran in 2014. Self developed questionnaire was used for assessment of social skill of respondents. Frequency and percentage distribution and t-test were used to analysis the score. Social skill was found ranging between high to good in majority adolescent boys and girls of the upper and middle socio-economic groups whereas, in the lower socio-economic group, it was found ranging between average to poor in majority adolescents. There was no significant gender difference found in social skill of adolescents.

KEY WORDS: Adolescents, Social skill, Socio-economic group

WOW TO CITE THIS PAPER : Pandey, Pallavi, Anshu and Mathur, Anjali (2020). A study on social skill of adolescent boys and girls across socio-economic groups. Asian J. Home Sci., 15 (2) : 367-371, DOI: 10.15740/HAS/AJHS/15.2/367-371. Copyright@ 2020: Hind Agri-Horticultural Society. 